\title{
Investigation of Aromatic/Aliphatic Polyimides as Dispersants for Single Wall Carbon Nanotubes
}

\author{
D.M. Delozier, ${ }^{\dagger}$ K.A. Watson, ${ }^{\dagger}$ J.G. Smith Jr., T.C. Clancy ${ }^{\dagger}$ and J.W. Connell \\ NASA Langley Research Center \\ Advanced Materials and Processing Branch
}

Hampton, VA 23681-2199

\begin{abstract}
$\underline{\text { Abstract }}$
Novel aromatic/aliphatic polyimides were prepared from 2,7-diamino-9,9'dioctylfluorene (AFDA) and aromatic dianhydrides. Upon investigating the effectiveness of these polyimides for dispersing single wall carbon nanotubes (SWNTs) in solution, three were discovered to disperse SWNTs in $N, N$-dimethylacetamide (DMAc). Two of these polyimides, one from 3,3',4,4'-oxydiphthalic anhydride (ODPA) and one from symmetric 3,3',4,4'-biphenyltetracarboxylic dianhydride (s-BPDA), were used to prepare nanocomposites. Homogeneous polyimide/SWNT suspensions from both polymers were used in the preparation of films and fibers containing up to $1 \mathrm{wt} \% \mathrm{SWNTs}$. The samples were thermally treated to remove residual solvent and the films were characterized for SWNT dispersion by optical and high resolution scanning electron microscopy (HRSEM). Electrical and mechanical properties of the films were also determined. Electrospun fibers were examined by HRSEM to characterize SWNT alignment and orientation.
\end{abstract}

Keywords: Nanocomposites, dispersant, polyimide

† National Institute of Aerospace, 144 Research Drive, Hampton, VA 23666 


\section{Introduction}

Polymer systems containing dispersed nanoparticles represent a class of materials with a combination of properties generally not obtainable in conventional polymers. Carbon nanotubes, especially single wall carbon nanotubes (SWNTs), are among the most attractive of all nanoparticles due to their high aspect ratio and desirable mechanical and electrical properties. The addition of SWNTs to polymers can change select material properties even at low loading levels when properly dispersed. For example, adding small amounts of SWNTs to insulating polymers such as polyimides can impart electrical conductivity while having little effect on the appearance, optical and mechanical properties of the material. This has been demonstrated in recent efforts to develop transparent, flexible, anti-static polyimides with low solar absorptivity for space applications $^{1-8}$.

Although some properties of polymers can be affected by the addition of small amounts of SWNTs, properties such as improved thermal conductivity are expected to require much higher loadings, nanotube alignment, and perhaps modification to the interface between the nanotube and the matrix. This represents a major challenge as it is more difficult to disperse SWNTs at higher weight loadings. The advantage of dispersing SWNT bundles to smaller bundles or single nanotubes is that the SWNT surface area of these tubes is greatly increased and much more of the polymer matrix is affected by the SWNTs. A larger surface area creates a larger interfacial area which in turn affects bulk properties of the composite. Thus, discovering new mechanisms for increasing the dispersion of SWNTs is one major driver for new technology in this area. 
There have been many developments in the dispersion of SWNTs in both aqueous and organic solvents as well as in polymers. There are four prominent methods for achieving dispersion: mechanical methods ${ }^{8,10}$, functionalizing the $\mathrm{SWNTs}^{11-20}$, using surfactants $^{21}$, and non-covalent modification by using small molecules and polymer dispersants $^{22-39}$. There are advantages and disadvantages associated with each of the listed methods. For example, the use of mechanical means like high powered sonication or shearing forces to disperse SWNTs is effective but can decrease the length and consequently alter the properties of the SWNTs. Surfactants work extremely well in aqueous solutions but are ineffective in organic solvents. Functionalization of SWNTs is also a viable means to enhance dispersion, but this method changes the hybridization of the carbon atoms on the SWNTs and thus the properties can also be changed. Perhaps the most effective means for dispersing SWNTs is the use of non-covalent modification, a technique that does not alter the properties of SWNTs. One potential disadvantage associated with non-covalent modification is that the dispersant must remain in the system to maintain dispersion. This may not be desirable since the dispersant can alter the properties of the final material, but if the dispersant has similar properties to the matrix or can serve as a matrix, then non-covalent modification can be very attractive.

We recently reported that non-covalent modification with ionomers prepared from AFDA and an aromatic bis(pyrylium salt) could be used to disperse SWNTs in organic solvents, and the dispersed suspensions could subsequently be blended with polyimides ${ }^{40}$. In these systems the ionomers worked well to disperse SWNTs, but the difficulty in preparing the ionomers rendered them somewhat unattractive for practical use. Difficulty arose from the fact that monomers used to synthesize the ionomers were not 
commercially available and the polymerization required high temperatures $\left(165^{\circ} \mathrm{C}\right)$. The purpose of the described work was to develop a dispersant for SWNTs that had similar dispersive properties as the previously reported ionomers but was more cost effective and practical to prepare. A room temperature polymerization involving the use of the same diamine used for the ionomer synthesis and commercially available dianhydrides was used in the preparation of polyimides. Representative polyimides were prepared and three polyimides were found to be effective dispersants for SWNTs. Suspensions containing up to $1 \mathrm{wt} \%$ SWNT in these polyimides were used to prepare films and electrospun fibers. The dispersion and orientation of SWNTs within the nanocomposites along with other select properties of these films are discussed herein.

\section{Experimental}

\subsection{Starting Materials}

Bucky Pearl SWNTs (Lot \# PO222, 90\% purity) were purchased from Carbon Nanotechnologies, Incorporated and used as received. 2,3,3',4'-Biphenyltetracarboxylic dianhydride (a-BPDA) was obtained from Ube Industries, Ltd. and recrystallized from a 1:1 mixture of toluene:acetic anhydride to yield white crystals, mp 196-198 ${ }^{\circ} \mathrm{C}$. S-BPDA (Chriskev Co., mp 297-298 ${ }^{\circ} \mathrm{C}$ ) and phthalic anhydride (PA) (Mallinkroft Specialty Chemical Co., mp $131{ }^{\circ} \mathrm{C}$ ) were used as received. Pyromellitic dianhydride (PMDA) was obtained from Allco Chemical Corporation and sublimed to provide white crystals sublimate, mp $284-286^{\circ} \mathrm{C}$. ODPA was obtained from Imitec, Inc. and sublimed to yield a white crystalline solid, mp $224-226{ }^{\circ} \mathrm{C}$. 4,4'-Perfluoroisopropylidiene dianhydride (6FDA) was obtained from Hoechst Celanese, Inc. and sublimed prior to use (mp 241- 
$\left.243{ }^{\circ} \mathrm{C}\right) . \quad 4,4^{\prime}-\left(4,4^{\prime}-\right.$ Isopropylidenediphenoxy)bis(phthalic anhydride) (BPADA) was obtained from GE Plastics, Inc. and dried at $150{ }^{\circ} \mathrm{C}$ prior to use. 2,7-diamino-9,9'dioctylfluorene (AFDA) was prepared according to a literature procedure. ${ }^{40}$ All other materials were purchased from commercial sources and used without further purification.

\subsection{Preparation of high molecular weight (HMW) polyimides}

Into a $100 \mathrm{~mL}$, three-necked flask equipped with nitrogen inlet, mechanical stirrer, and drying tube were placed AFDA (10.02 g, $23.8 \mathrm{mmol})$ and DMAc $(50 \mathrm{~mL})$. The mixture stirred until the diamine completely dissolved. ODPA (7.39 g, $23.8 \mathrm{mmol})$ was added as a powder followed by additional DMAc $(30 \mathrm{~mL})(18.8 \%$ solids $)$. After the intermediate poly(amide acid) (PAA) stirred for $\sim 16 \mathrm{~h}$, pyridine (5.65 g) and acetic anhydride $(7.29 \mathrm{~g})$ were added and the solution stirred for $\sim 16 \mathrm{~h}$. DMAc $(310 \mathrm{~mL})$ was then added to the solution followed by $0.5 \mathrm{~h}$ of stirring. The solution was subsequently poured into water $(2 \mathrm{~L})$ in a Waring blender. The resulting powder was washed with water and dried by heating to $100{ }^{\circ} \mathrm{C}$ for $24 \mathrm{~h}$.

\subsection{Preparation of endcapped, low molecular weight polyimides}

Into a $500 \mathrm{~mL}$, three-necked flask equipped with nitrogen inlet, mechanical stirrer, and drying tube were placed AFDA (11.50 g, $27.3 \mathrm{mmol})$ and DMAc $(50 \mathrm{~mL})$. The reaction mixture stirred until the diamine completely dissolved. s-BPDA (7.76 g, $26.4 \mathrm{mmol})$ and PA $(0.2842 \mathrm{~g}, 1.9 \mathrm{mmol})$ were added as powders followed by additional DMAc $(50 \mathrm{~mL})$. After the reaction mixture stirred for $\sim 16 \mathrm{~h}$, pyridine $(6.49 \mathrm{~g})$ and acetic anhydride $(8.37 \mathrm{~g})$ were added and the solution stirred for $\sim 16 \mathrm{~h}$. DMAc $(300 \mathrm{~mL})$ was 
then added and the solution stirred for $\sim 0.5 \mathrm{~h}$ after which the solution was poured into water $(2 \mathrm{~L})$ in a Waring blender. The resulting powder was washed with water and dried by heating at $100^{\circ} \mathrm{C}$ for $\sim 24 \mathrm{~h}$. The number average molecular weight $\left(\mathrm{M}_{\mathrm{n}}\right)$ was 9410 $\mathrm{g} / \mathrm{mol}$ as determined by gel permeation chromatography (GPC).

\subsection{Determination of dispersant effectiveness}

Polyimides were screened for effectiveness at dispersing SWNTs at room temperature by the following method:

Into a $20 \mathrm{~mL}$ scintillation vial were placed SWNT $(1.0 \mathrm{mg})$ and DMAc $(5.0 \mathrm{~g})$. The vial was submerged in a Branson 2510 Bransonic $^{\circledR}$ ultrasonic cleaner bath operating at $42 \mathrm{KHz}$ for $10 \mathrm{~min}$ followed by the addition of the polyimide $(20.0 \mathrm{mg})$. Sonication was administered for another $10 \mathrm{~min}$ and the vial was then immediately removed from the bath and visually examined for appearance. The temperature of the sonicator bath was at ambient conditions and did not change significantly during these experiments. Good dispersion was indicated by a visually homogeneous solution without any visual particulates.

\subsection{Preparation of polyimide/SWNT mixtures}

The following is a representative procedure for preparing polyimide/SWNT mixtures:

Into a $20 \mathrm{~mL}$ scintillation vial were placed SWNTs $(10 \mathrm{mg})$ and DMAc $(7.15 \mathrm{~g})$. The suspension was sonicated in a Branson 2510 Bransonic $^{\circledR}$ ultrasonic cleaner bath operating at $42 \mathrm{KHz}$ for $\sim 1 \mathrm{~h}$ followed by the addition of polyimide $(0.1 \mathrm{~g})$. The 
suspension was then subjected to $\sim 0.5 \mathrm{~h}$ sonication followed by two more polyimide additions of $0.2 \mathrm{~g}$ each with $10 \mathrm{~min}$ of sonication after each addition. The bath water reached temperatures of $\sim 45-55{ }^{\circ} \mathrm{C}$ after $1 \mathrm{~h}$ of sonication. A final polyimide addition $(0.5 \mathrm{~g})$ was then made and the mixture placed on a mechanical shaker for $\sim 3 \mathrm{~h}$. The polyimide/SWNT mixtures were used to cast thin films.

\subsection{Thin films}

Thin films were cast from control solutions (polymer only) and nanocomposite mixtures. The neat solutions and the nanocomposite mixtures were doctored onto plate glass and dried to a tack-free state under flowing nitrogen at room temperature in a low humidity chamber. Solvent removal was done under flowing air after drying to a tackfree film as follows: $1 \mathrm{~h}$ each at 100,200 , and $0.5 \mathrm{~h}$ at $220{ }^{\circ} \mathrm{C}$. Thin-film tensile properties were determined according to ASTM D882 at room temperature using five specimens from each film at a crosshead speed rate of $0.5 \mathrm{~mm} / \mathrm{min}$.

\subsection{Electrospun Fibers}

Nanocomposite mixtures ( $\sim 18 \%$ solids) were transferred to a $5 \mathrm{~mL}$ syringe which was placed in a syringe infusion pump (Fisher Scientific, Suwanee, GA). A high voltage power supply (Spellman High Voltage Electronics Corp., Hauppage, NY) was used to charge the syringe tip to $28 \mathrm{~V}$. The nanocomposite mixture was simultaneously pumped at a constant rate of $3.3 \mathrm{~mL} / \mathrm{h}$ under the applied voltage. The charge on the mixture eventually overwhelmed its surface tension, and a jet was ejected from the needle tip to a grounded collector. The grounded collector in this setup was a spinning mandrel located 
$20 \mathrm{~cm}$ away from the syringe tip oriented parallel to the tip. The fibers were collected on the spinning mandrel resulting in a fibrous mat.

\subsection{Characterization}

High-resolution scanning electron microscopy (HRSEM) images were obtained on a Hitachi S-5200 field emission scanning electron microscopy system. Optical microscopy was performed using an Olympus $\mathrm{BH}-2$ microscopeat a magnification of 500x. Surface resistivity was determined according to ASTM D-257-99 using a Prostat ${ }^{\mathbb{Q}}$ PSI-870 Surface Resistance and Resistivity Indicator operating at 9V, and reported as an average of three readings. Volume resistivity was determined using a Prostat ${ }^{\circledR}$ PRS-801 Resistance System with a PRF-911 Concentric Ring Fixture operating at $10-100$ V according to ASTM D-257. Raman spectroscopy was performed using a Thermo Nicolet Almega Dispersive Raman spectrometer equipped with a $785 \mathrm{~nm}$ laser. Inherent viscosities were obtained for $0.5 \%(\mathrm{w} / \mathrm{v})$ solutions in DMAc at $25^{\circ} \mathrm{C}$. A Waters $150 \mathrm{C}$ GPC system was employed using an RI detector and a Viscotek viscometer. Waters Stryagel HT3, HT4 and HT6E size exclusion columns were hooked up in tandem and equilibrated with $\mathrm{N}$-methyl-2-pyrrolidinone (NMP) $(\mathrm{w} / 0.02 \mathrm{M} \mathrm{LiBr})$ at a column temperature of $60{ }^{\circ} \mathrm{C}$. The flow rate was set to $1 \mathrm{~mL} / \mathrm{min}$. A calibration curve was generated using polystyrene molecular weight standards from Polymer Laboratories. Samples were weighed out and high purity, anhydrous NMP (w/0.02 M LiBr) was added to each sample and shaken for several minutes to completely dissolve the sample. The samples were then filtered through a $0.2 \mu$ syringe filter (PTFE filter matrix) to remove any insoluble material prior to injection on the column. A $100 \mu \mathrm{L}$ sample was injected 
into the column and data collected using Viscotek GPC software. Each sample was run in duplicate and the data from each run analyzed using the software to calculate the $\mathrm{M}_{\mathrm{n}}$ and weight average molecular weight $\left(\mathrm{M}_{\mathrm{w}}\right)$ for each sample.

\section{Results and Discussion}

\subsection{Preparation of Polyimides}

Polyimides were prepared from AFDA and aromatic dianhydrides (Figure 1). Stoichiometric amounts of the monomers were used in the synthesis to achieve the highest molecular weight possible.<smiles>O=C1OC(=O)c2cc(C(c3ccc4c(c3)C(=O)OC4=O)(C(F)(F)F)C(F)(F)F)ccc21</smiles><smiles>O=C1OC(=O)c2cc(Oc3ccc4c(c3)C(=O)OC4=O)ccc21</smiles><smiles>CC(C)(c1cccc(Oc2ccc3c(c2)C(=O)OC3=O)c1)c1cccc(Oc2ccc3c(c2)C(=O)OC3=O)c1</smiles><smiles>O=C1OC(=O)c2cc(-c3ccc4c(c3)C(=O)OC4=O)ccc21</smiles><smiles>O=C1OC(=O)c2cc(-c3cccc4c3C(=O)OC4=O)ccc21</smiles> 


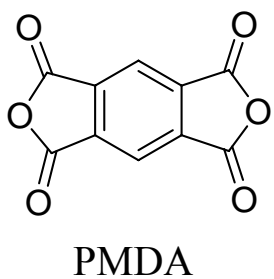

Figure 1. Dianhydrides used in comparison study

The poly(amide acid)s had inherent viscosities ranging from 0.52 to $1.37 \mathrm{dL} / \mathrm{g}$ (Table 1) indicating medium to high polymer formation. Solubility tests indicated that the corresponding polyimides (P2-P5) would readily dissolve in DMAc. P1 and P6 would only partially dissolve in DMAc when $20 \mathrm{mg}$ of the polyimide was placed in $5 \mathrm{~g}$. The reduced solubility can be explained by the more rigid dianhydrides used with P1 and P6.

Table 1. Properties of HMW polyimides

\begin{tabular}{|c|c|c|c|}
\hline Sample & Dianhydride & $\begin{array}{c}\text { Inherent } \\
\text { Viscosity (PAA) } \\
(\mathrm{dL} / \mathrm{g})\end{array}$ & $\begin{array}{c}\text { Soluble in } \\
\text { DMAc at } 25^{\circ} \mathrm{C}\end{array}$ \\
\hline P1 & s-BPDA & 1.37 & Partially \\
\hline P2 & a-BPDA & 1.14 & Yes \\
\hline P3 & ODPA & 0.83 & Yes \\
\hline P4 & 6FDA & 0.65 & Yes \\
\hline P5 & BPADA & 0.61 & Yes \\
\hline P6 & PMDA & 0.52 & Partially \\
\hline
\end{tabular}

To increase the solubility of the P1 polymer, a series of lower molecular weight oligomers having the same structure as P1 were prepared at 6.9\% (EP1), 4.7\% (EP2), and $3.5 \%$ (EP3) stoichiometric offset and endcapped with PA (Figure 2). 


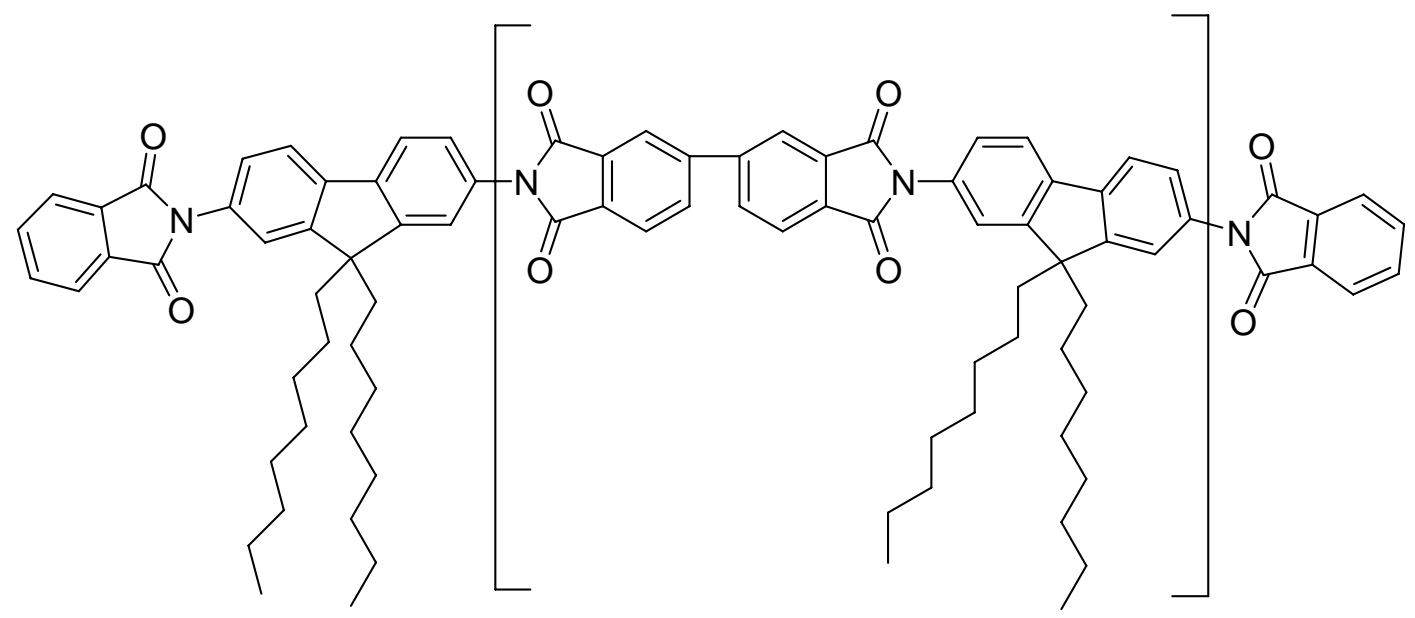

Figure 2. Imide oligomers from AFDA and s-BPDA

These imide oligomers were soluble in DMAc to at least $20 \mathrm{wt} \%$ solids and were be characterized by GPC. The GPC data for the oligomers as well as for P3 are shown in Table 2.

Table 2. Properties of controlled MW AFDA-sBPDA polyimides

\begin{tabular}{|c|c|c|c|c|}
\hline Sample ID & $\begin{array}{c}\text { Mn } \\
(\mathrm{g} / \mathrm{mol})\end{array}$ & $\begin{array}{c}\text { Polydisperity } \\
(\mathrm{PD})\end{array}$ & $\begin{array}{c}\text { Intrinsic } \\
\text { Viscosity } \\
(\mathrm{dL} / \mathrm{g})\end{array}$ & $\begin{array}{c}\text { Soluble in } \\
\text { DMAc at } 25^{\circ} \mathrm{C}\end{array}$ \\
\hline EP1 & 6860 & 2.3 & 0.25 & Yes \\
\hline EP2 & 8250 & 2.3 & 0.33 & Yes \\
\hline EP3 & 9410 & 2.0 & 0.44 & Yes \\
\hline P3 & 17050 & 2.94 & 0.63 & Yes \\
\hline
\end{tabular}

3.2. Dispersing SWNTs and preparation of nanocomposites

The polyimides were then tested for their effectiveness in dispersing SWNTs in DMAc. Upon sonicating the neat SWNTs in DMAc, the SWNT chunks would swell yielding visibly suspended agglomerates. After adding polyimide to the SWNT suspensions, the interaction between the polyimides and the SWNTs was visually 
observed. The result of a favorable interaction between polyimides and SWNTs was a homogeneous suspension devoid of any visible SWNT agglomerates, while unfavorable interactions resulted in SWNT suspensions with no effective change when compared to the neat samples. Data from the qualitative assessment of polyimide-SWNT interaction is recorded in Table 3.

Table 3. Dispersant Effectiveness

\begin{tabular}{|c|c|}
\hline Sample & $\begin{array}{c}\text { Disperses } \\
\text { SWNTs }\end{array}$ \\
\hline P1 & Yes \\
\hline P2 & No \\
\hline P3 & Yes \\
\hline P4 & No \\
\hline P5 & No \\
\hline P6 & Yes \\
\hline EP1 & No \\
\hline EP2 & No \\
\hline EP3 & Partial \\
\hline
\end{tabular}

Polymers P2, P4, P5, EP1 and EP2 exhibited unfavorable interactions once added to the suspensions as SWNT agglomerates were visually apparent. However, polymers P1, P3, and P6 exhibited favorable interactions with the SWNTs. Surprisingly, P1 and P6 were effective at dispersing SWNTs even though these polyimides were only slightly soluble in DMAc. The difference in polymer/SWNT interaction between P1 and P2 was peculiar because the dianhydrides were isomers. The results indicate that proper 
alignment of the polymer with the nanotube could not be achieved when the asymmetric isomer of BPDA was used. This is consistent with findings that polymers with more bent isomers of BPDA exhibited weaker intermolecular interactions. ${ }^{41}$

The combination of polymer solubility with the ability to disperse SWNTs was necessary to prepare nanocomposite films from these polyimides. The initial screening studies indicated P3 to be the best choice. The results also indicated the EP3 polymer to be a good candidate. Although EP3 was not successful at completely dispersing SWNTs in the solvent at the ratio used for the visual test $(20 \mathrm{mg}$ polymer/1 $\mathrm{mg}$ SWNT), suspensions with EP3 were much improved when compared to neat SWNT suspensions. It was assumed that higher polymer concentrations would yield completely homogeneous suspensions. This was later confirmed as homogeneous suspensions were afforded during film preparation. Higher MW polymers may have also proven successful, but EP3 was slow to dissolve and thus no attempt was made to use higher molecular weight versions for film preparation.

\subsection{Preparation of nanocomposites}

The other polymer chosen for nanocomposite preparation was the P3 polymer shown in Figure 3 and EP3 (see Figure 1). 


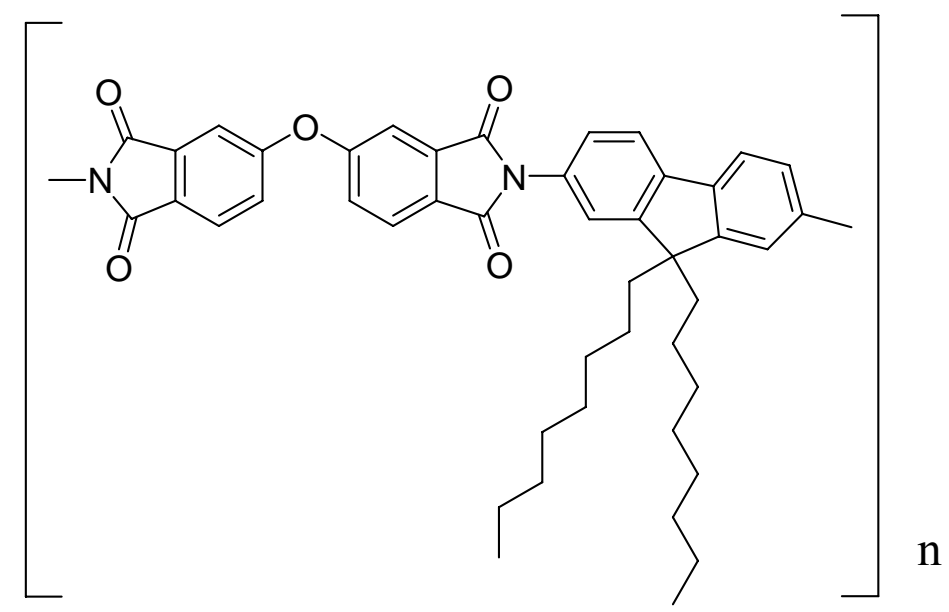

Figure 3. P3 polyimide

The first step in preparing nanocomposites was to disperse SWNTs in solvent via sonication. Additional sonication and agitation were administered after the polymer was added. Solutions containing $0.1,0.5$ and $1 \mathrm{wt} \% \mathrm{SWNT}$ were then doctored onto glass and films prepared. In the case of polyimide P3, fibers were also prepared from the 1 wt $\%$ sample.

Raman spectroscopy showed similar results for these films compared to those obtained for previously prepared ionomer based nanocomposites and thus it was assumed that the chemistry of the SWNTs was unaffected during nanocomposite preparation. ${ }^{43}$

\subsection{Optical and HRSEM images of nanocomposite films}

Visual examination of nanocomposite films revealed darker films as the SWNT loading level was increased. However, transparency was maintained in all the films except the $1 \mathrm{wt} \%$ P3 film which was slightly hazy. Optical microscopy, which is generally used to visualize bundles and agglomerates of SWNTs, was used to further characterize SWNT dispersion in the nanocomposite films. Figure 4 confirms the 
presence of bundles, which appear as patterns of black lines, in all the EP3 films. The bundles are evenly distributed throughout the matrix in the $0.1 \%$ and $0.5 \mathrm{wt} \%$ EP3 films. However, agglomerates are noticeable in the 1\% EP3 film indicating incomplete dispersion of SWNT bundles. The P3 films (Figure 5) exhibited similar dispersion characteristics but a few agglomerates were also noticed in the $0.5 \%$ SWNT loaded films. The optical microscopy data revealed that the EP3 polymer was better at dispersing SWNTs at higher loadings. This is most likely related to polymer structure as the lowering of the MW was shown to diminish the dispersing power of the polyimides.
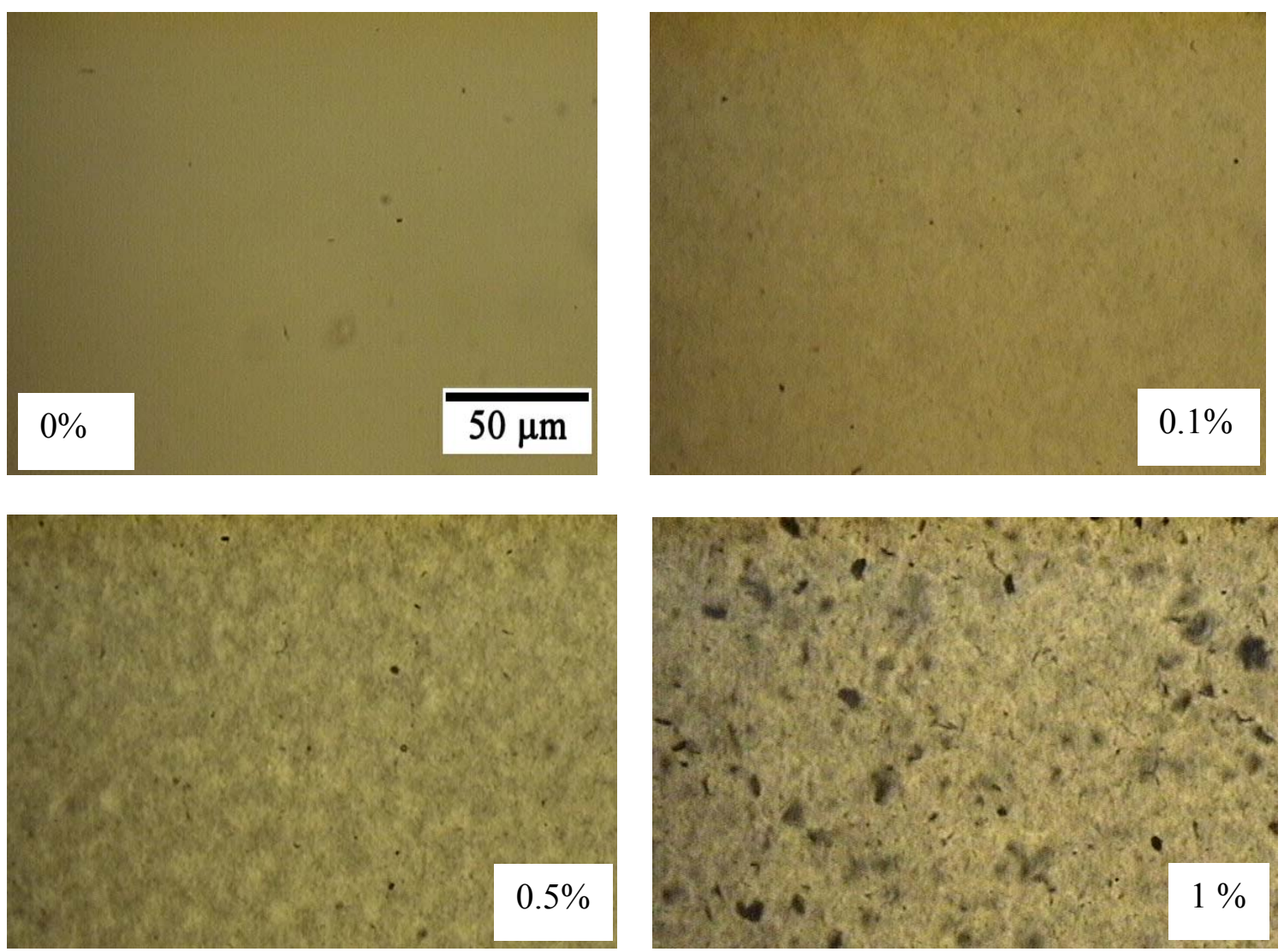

Figure 4. Optical microscopy of EP3 films (scale bar for all images in Figures 4 and 5) 

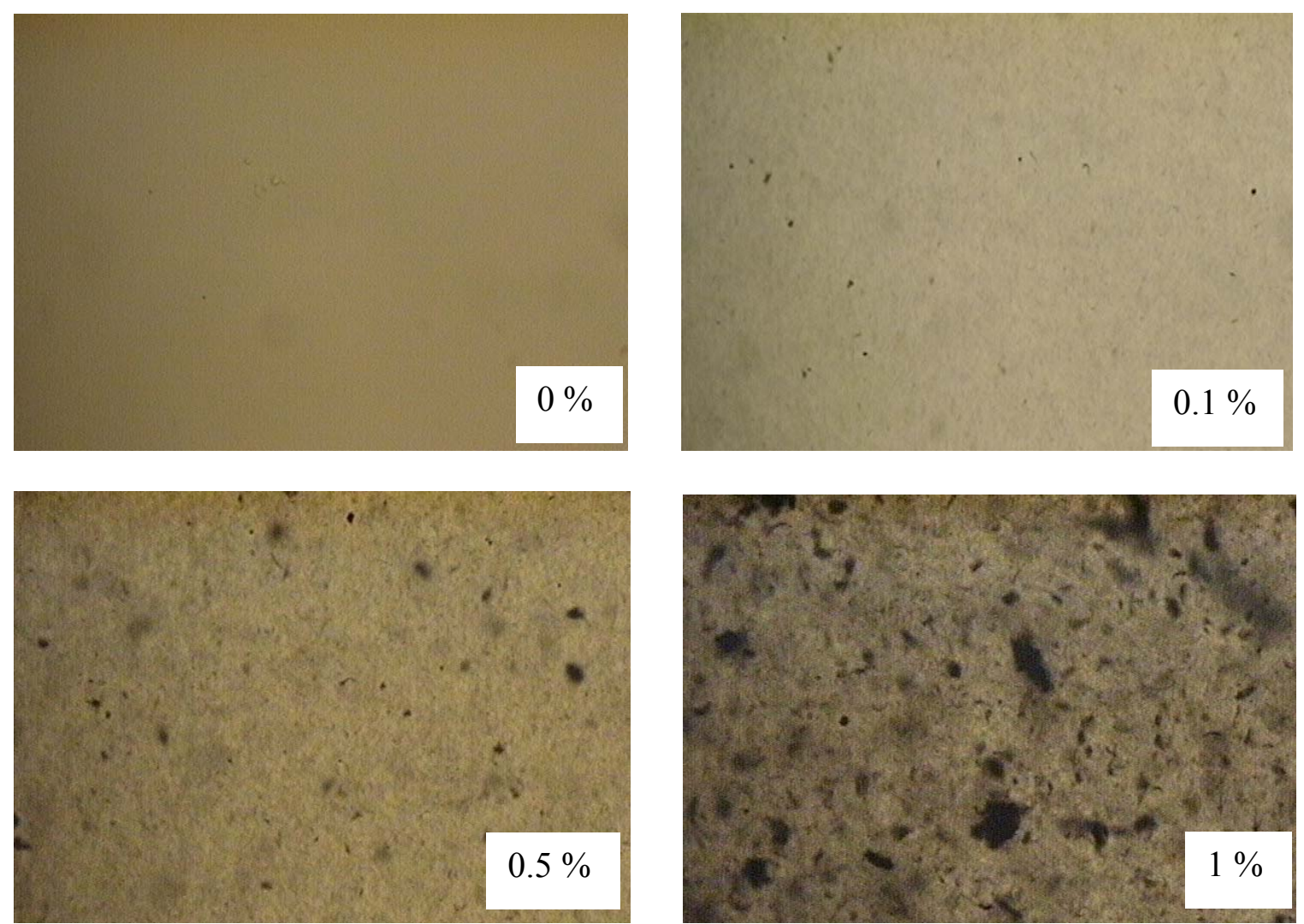

Figure 4. Optical microscopy of P3 nanocomposite films

HRSEM was also used to examine SWNT dispersion in the films. HRSEM images were taken while the film surface was oriented normal to the beam. The contrast between SWNTs and polymer is due to variations in the beam-induced electric field and allows for a direct assessment of SWNT dispersion within polymer matrices. ${ }^{20,38}$ Obtaining $^{2}$ HRSEM images was only possible for those films with sufficient conductivity to withstand exposure to the electron beam. Therefore, the $0.1 \%$ EP3 and P3 films could not be imaged. Although the $0.5 \%$ and $1 \%$ EP3 films were not highly conductive (Table $3)$, they exhibited unusually high stability in the beam at high voltages $(20 \mathrm{kV})$. In all the films, SWNTs appeared to be uniformly dispersed in arrays of rope-like networks. In both the $0.5 \%$ and the $1 \%$ EP3 samples, the SWNTs were randomly oriented with small bundle sizes $(<10 \mathrm{~nm})$ (Figure 6). Nearly identical images were obtained for the P3 
nanocomposites except that the $0.5 \%$ sample was not as stable under the electron beam.

This is noticed in the darkening of the images and is consistent with the lower conductivity values obtained for the $0.5 \% \mathrm{P} 3$ film than for the $0.5 \%$ EP3 film (Section $3.5)$.
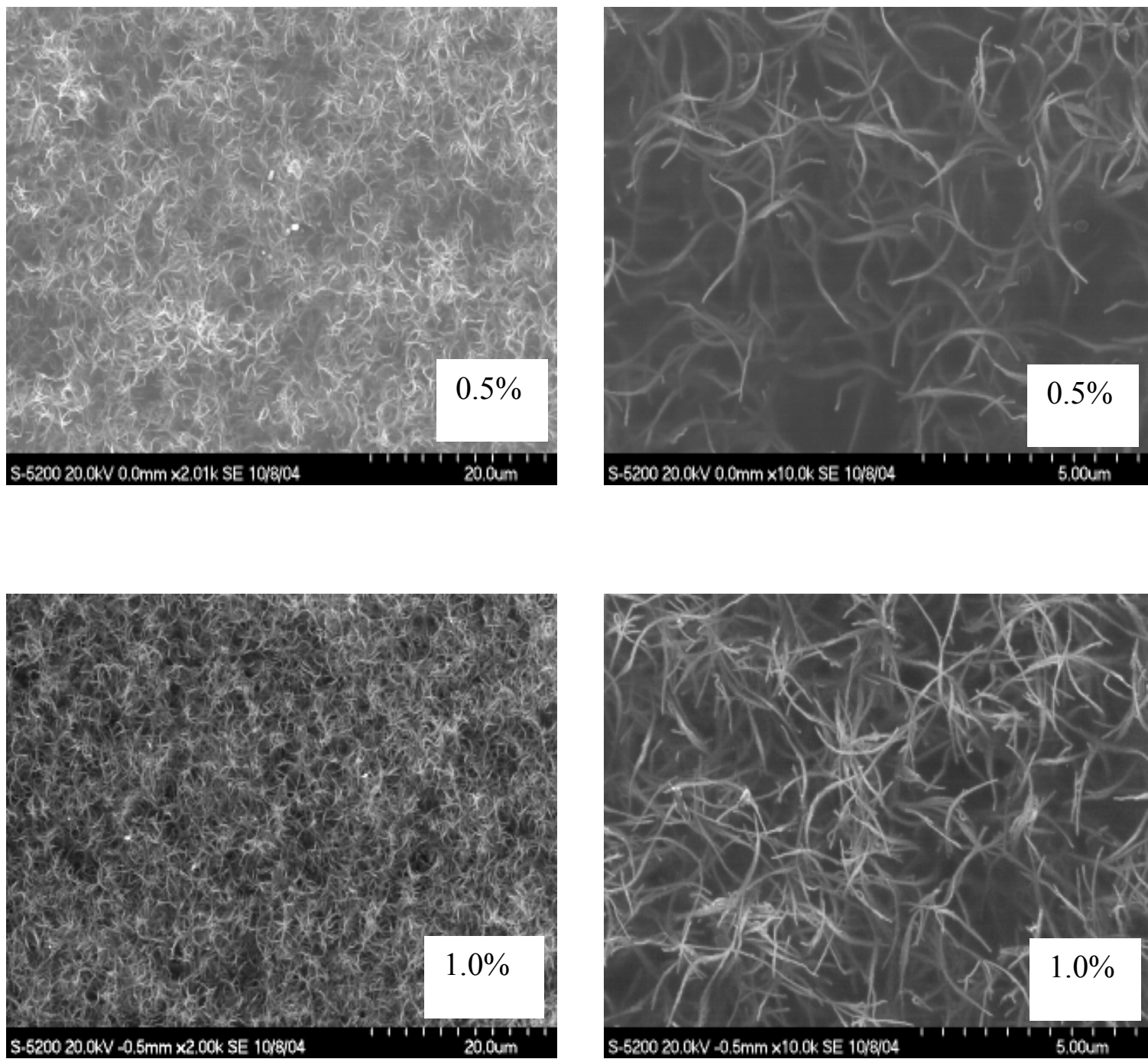

Figure 6. HRSEM images of EP3 nanocomposites 

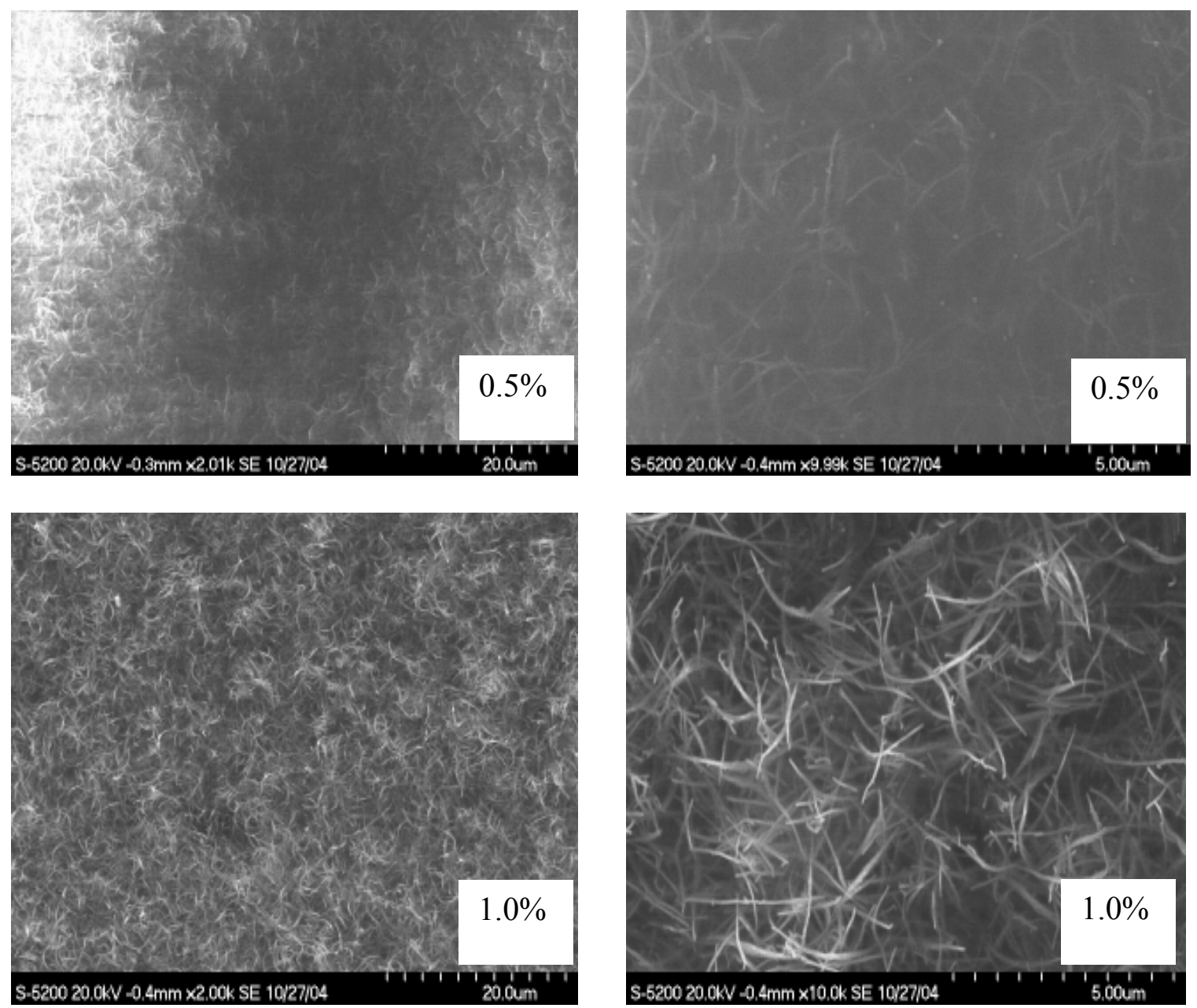

Figure 7. HRSEM images of $\mathrm{P} 3$ nanocomposites

\subsection{Electrical properties of nanocomposite films}

Conductivity of polymer films can be affected by addition and the percolation threshold for electrical conductivity usually occurs below $0.1 \mathrm{wt} \% \mathrm{SWNT}^{1-8,43}$. The resistivity values for EP3 films and P3 films (Tables 4 and 5, respectively) show that percolation occurred above $0.1 \%$ in the case of EP3 and above $0.5 \%$ for the P3 films. The reason for the increased loading needed to reach percolation is not understood. However, one suggestion is that the high affinity of the polymer for the SWNT surface allows the polymers to completely coat and insulate the SWNT surface. Thus, the 
SWNTs and SWNT bundles are coated with the insulative polymer in such a way as to prevent the charge from transferring from one SWNT bundle to another. The surface and volume resistivity values for the samples after reaching percolation are similar to those typically found in polyimide/SWNT films. For example a previously prepared LaRCCP2 film containing $0.05 \mathrm{wt} \%$ SWNT had a surface resistivity of $10^{8} \Omega /$ square and a volume resistivity of $10^{9} \Omega \mathrm{cm}^{7}$

Table 4. Resistivity of EP3-SWNT films

\begin{tabular}{|c|c|c|c|}
\hline Sample & $\begin{array}{c}\text { SWNT Loading } \\
(\mathrm{wt} \%)\end{array}$ & $\begin{array}{c}\text { Surface Resistivity } \\
(\Omega / \text { square })\end{array}$ & $\begin{array}{c}\text { Volume Resistivity } \\
(\Omega \mathrm{cm})\end{array}$ \\
\hline EP3 & 0 & $3.23 \times 10^{12}$ & $9.76 \times 10^{14}$ \\
\hline EP3 & 0.1 & $1.43 \times 10^{12}$ & $3.01 \times 10^{13}$ \\
\hline EP3 & 0.5 & $3.67 \times 10^{9}$ & $1.25 \times 10^{10}$ \\
\hline EP3 & 1 & $4.03 \times 10^{7}$ & $3.4 \times 10^{9}$ \\
\hline
\end{tabular}

Table 5. Resistivity of P3-SWNT films

\begin{tabular}{|c|c|c|c|}
\hline Sample & $\begin{array}{c}\text { SWNT Loading } \\
(\mathrm{wt} \%)\end{array}$ & $\begin{array}{c}\text { Surface Resistivity } \\
(\Omega / \text { square })\end{array}$ & $\begin{array}{c}\text { Volume Resistivity } \\
(\Omega \mathrm{cm})\end{array}$ \\
\hline P3 & 0 & $2.97 \times 10^{12}$ & $7.19 \times 10^{14}$ \\
\hline P3 & 0.1 & $2.01 \times 10^{12}$ & $7.86 \times 10^{14}$ \\
\hline P3 & 0.5 & $1.21 \times 10^{12}$ & $2.94 \times 10^{14}$ \\
\hline P3 & 1 & $3.97 \times 10^{8}$ & $6.16 \times 10^{7}$ \\
\hline
\end{tabular}

3.6. Tensile properties of nanocomposite films

Tensile properties of polymer/SWNT nanocomposites depend on the orientation of SWNTs within each sample. For example, large increases in modulus and strength are reported if SWNTs are aligned ${ }^{42}$ but if random orientation is present, the mechanical properties are not improved by the addition ${ }^{43}$. Optical microscopy and HRSEM for both the P3 and EP3 films show very little SWNT alignment and thus the nanocomposite films were not expected to show large increases in either tensile modulus or strength. However, moduli in both the P3 films and EP3 films (Table 6 and 7, respectively) did 
increase slightly as the SWNT concentration increased. In both polymer systems there were only minor differences in film strength as a function of SWNT loading. Conversely, elongations of $\mathrm{P} 3$ nanocomposites were considerably altered. The reason for the sharp drop in elongation in the $\mathrm{P} 3$ nanocomposites is not clear but may be a result of stress concentration regions introduced by the nanotube bundles or larger agglomerates at higher weight loadings. This change in elongation was not noticed in the EP3 polymer perhaps because the neat sample had a low elongation to begin with.

Table 6. Room temperature thin film tensile properties of EP3 nanocomposites

\begin{tabular}{|c|c|c|c|c|}
\hline Sample & $\begin{array}{c}\text { SWNT Loading } \\
(\mathrm{wt} \%)\end{array}$ & $\begin{array}{c}\text { Modulus } \\
(\mathrm{GPa})\end{array}$ & $\begin{array}{c}\text { Strength } \\
(\mathrm{MPa})\end{array}$ & $\begin{array}{c}\text { Elongation } \\
(\%)\end{array}$ \\
\hline EP3 & 0 & $2.38 \pm 0.07$ & $72.3 \pm 3.1$ & $7 \pm 1.5$ \\
\hline EP3 & 0.1 & $2.41 \pm 0.00$ & $74.2 \pm 1.4$ & $6 \pm 1.0$ \\
\hline EP3 & 0.5 & $2.46 \pm 0.03$ & $77.1 \pm 0.8$ & $9 \pm 0.5$ \\
\hline EP3 & 1 & $2.61 \pm 0.02$ & $76.5 \pm 2.4$ & $7 \pm 1.5$ \\
\hline
\end{tabular}

Table 7. Room temperature thin film properties of $\mathrm{P} 3$ nanocomposites

\begin{tabular}{|c|c|c|c|c|}
\hline Sample & $\begin{array}{c}\text { SWNT Loading } \\
(\mathrm{wt} \%)\end{array}$ & $\begin{array}{c}\text { Modulus } \\
(\mathrm{GPa})\end{array}$ & $\begin{array}{c}\text { Strength } \\
(\mathrm{MPa})\end{array}$ & $\begin{array}{c}\text { Elongation } \\
(\%)\end{array}$ \\
\hline P3 & 0 & $1.57 \pm 0.02$ & $66.3 \pm 3.3$ & $49 \pm 6.1$ \\
\hline P3 & 0.1 & $1.58 \pm 0.03$ & $57.1 \pm 0.8$ & $16 \pm 0.5$ \\
\hline P3 & 0.5 & $1.73 \pm 0.03$ & $60.9 \pm 1.4$ & $21 \pm 1.2$ \\
\hline P3 & 1 & $1.71 \pm 0.02$ & $59.6 \pm 1.1$ & $14 \pm 5.0$ \\
\hline
\end{tabular}

3.7. Computer simulation of polymer-nanotube systems.

In order to examine the nature of the interaction between the polymer matrix and SWNTs, molecular dynamics (MD) simulations were performed. The experimental results indicate that P1 (s-BPDA) is able to disperse the carbon nanotubes while the asymmetric isomer P2 (a-BPDA) does not. Since these two polymers are identical in chemical constituency, differing only in the geometry of the attachment about the 
biphenyl linkage, modeling was used to gain insight into the mechanisms influencing the different behavior of these two isomers with the nanotubes.

In the molecular modeling, nine chains of molecular weight $5400 \mathrm{~g} / \mathrm{mol}$ each have been simulated with a $4 \mathrm{~nm}$ length section of a SWNT. These simulations were performed in fully atomistic detail with applied periodic boundary conditions. Three statistically independent models were prepared for each of the two polymer matrix types. The initial configurations were prepared by arranging the chains and the nanotube at low density and condensing the system with constant pressure MD. This was followed by $200 \mathrm{ps}$ of constant pressure MD at $300 \mathrm{~K}$. The same procedure was applied to generate bulk samples without the nanotube. Figure 8 shows the radial density of the polymer/nanotube system as a function of distance from the center of the nanotube. The large peak at 7-8 $\AA$ represents the SWNT wall. The data in this figure shows that both polymers exhibit similar density profiles. 


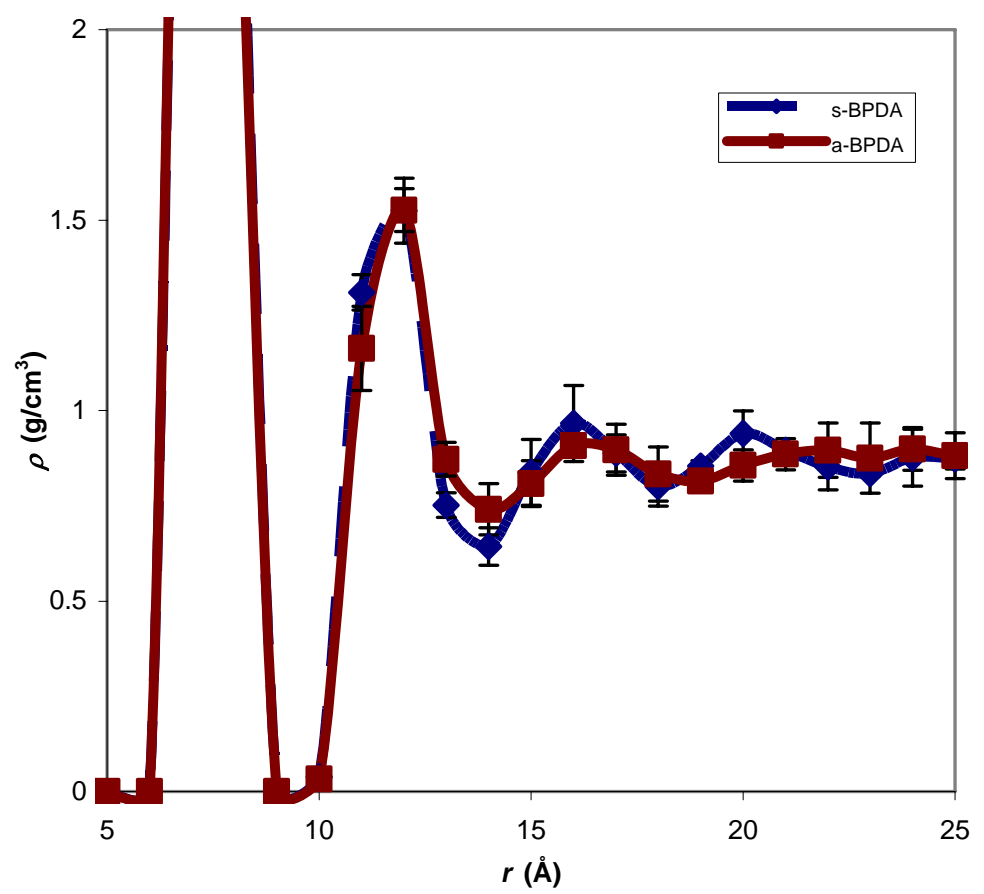

Figure 8. Radial density of the polymer-nanocomposite systems

Energetics of the two nanocomposite systems were also studied using the following methodology. The comparative interfacial energy, $E_{\text {interface, }}$ between the nanotube and the polymer for each polymer type is estimated from equation 1 ,

$$
E_{\text {interface }}=E_{\text {nanocomposite }}-E_{\text {nanotube }}-E_{\text {bulk polymer }}+E_{\text {tube extract }},
$$

where $E_{\text {nanocomposite }}$ is the energy of the system with the nanotube embedded in the polymer, $E_{\text {nanotube }}$ is the energy of the isolated nanotube, and $E_{\text {bulk polymer }}$ is the energy of the bulk polymer. $E_{\text {tube extract }}$ is the energy involved in extracting one nanotube from the middle of a system of a nanotube surrounded by six hexagonally packed nanotubes. This group of seven nanotubes is simulated in the same as way done for the polymer/nanotube system, where periodic boundary conditions are applied in the $\mathrm{z}$ direction along the axis of the tube. The comparative interfacial energy is converted to a surface energy in ergs $/ \mathrm{cm}^{2}$ by estimating the interfacial energy using a diameter of $10.5 \AA$. This value was 
chosen from consideration of Figure 8 and is arbitrarily but consistently applied. Results of the comparative interfacial energy calculation are shown in Table 8. The total energy is the sum of contributions due to the bond, angle, dihedral, improper and nonbond terms. The dihedral energy of the s-BPDA/AFDA polymer is significantly lowered in the presence of the carbon nanotube, indicating that the s-BPDA isomer can adopt an energetically preferred conformation at the interface while the a-BPDA isomer does not. This would appear to be the primary influence for the results given in Table 3 with regard to these two isomers.

Table. 8 Comparative interfacial energies (ergs $/ \mathrm{cm}^{2}$ ) for two polymer/nanotube systems studied (P3 and EP3)

\begin{tabular}{|l|c|c|}
\hline $\begin{array}{l}\text { Energy } \\
\left(\mathrm{ergs} / \mathrm{cm}^{2}\right)\end{array}$ & $\begin{array}{c}a \text {-BPDA } \\
\text { AFDA }\end{array}$ & $\begin{array}{c}s \text {-BPDA } \\
\text { AFDA }\end{array}$ \\
\hline Total & 65 & 31 \\
\hline bond & 1 & 6 \\
\hline angle & 12 & 9 \\
\hline dihedral & -5 & -59 \\
\hline improper & 0 & -1 \\
\hline nonbond & 57 & 76 \\
\hline
\end{tabular}

For illustration purposes, a short simulation of a single s-BPDA/AFDA polymer chain in the presence of a nanotube illustrates how the polymer can adopt the preferred conformation. This simulation was performed by removing eight of the chains from the bulk polymer/nanotube simulation, essentially exposing the polymer and the nanotube to vacuum. This results in the arrangement depicted in Figure 9 after approximately $10 \mathrm{ps}$ of MD simulation at $300 \mathrm{~K}$. Attempts to generate a similar picture with the a-BPDA AFDA isomer resulted in the chain folding up and moving away from the tube. 


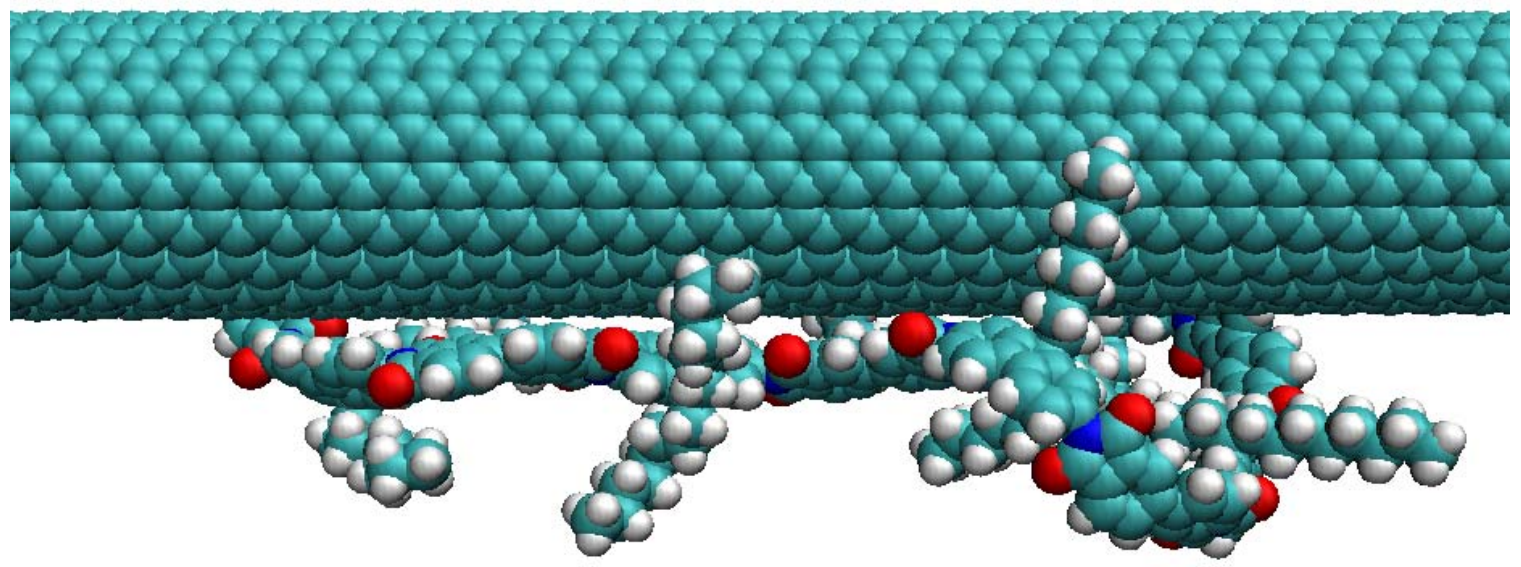

Figure 9. A single s-BPDA/AFDA chain in the presence of a nanotube illustrates how the polymer can adopt the preferred conformation. 


\subsection{Characterization of electrospun fibers}

The $1 \mathrm{wt} \%$ P3 suspension that was used in film preparation was also used to prepare fibers by electrospinning. The fibers were collected as mats which had enough integrity to endure physical handling. Further mechanical property testing of the fibers was not considered due to the lack of proper testing equipment. However, conductivity of the fiber mat could be measured by a handheld conductivity meter and the sample showed no increase in conductivity over the neat sample. However, a film prepared at the same wt\% loading did show lowered resistivity (Table 5 ).

The orientation of SWNTs in the fibers was of interest and the $1 \mathrm{wt} \%$ fiber was characterized by HRSEM. Upon analysis, it was observed that the fibers could withstand large voltages $(20 \mathrm{kV})$ as in the case of more conductive films. This indicated that charge was dissipated by some mechanism not detectable with the conductivity meter. Although the $1 \%$ sample could withstand beam exposure, SWNTs could not be imaged inside the as-prepared fibers. Thus, a portion of the fiber mat was placed in an air oven at $350{ }^{\circ} \mathrm{C}$

for $1 \mathrm{~h}$. After heating, the SWNTs were seen in the interior of the bundle (Figure 10) but at this concentration they did not appear to be completely aligned along the axis of the $1.5-2.0 \mu \mathrm{m}$ fiber. 


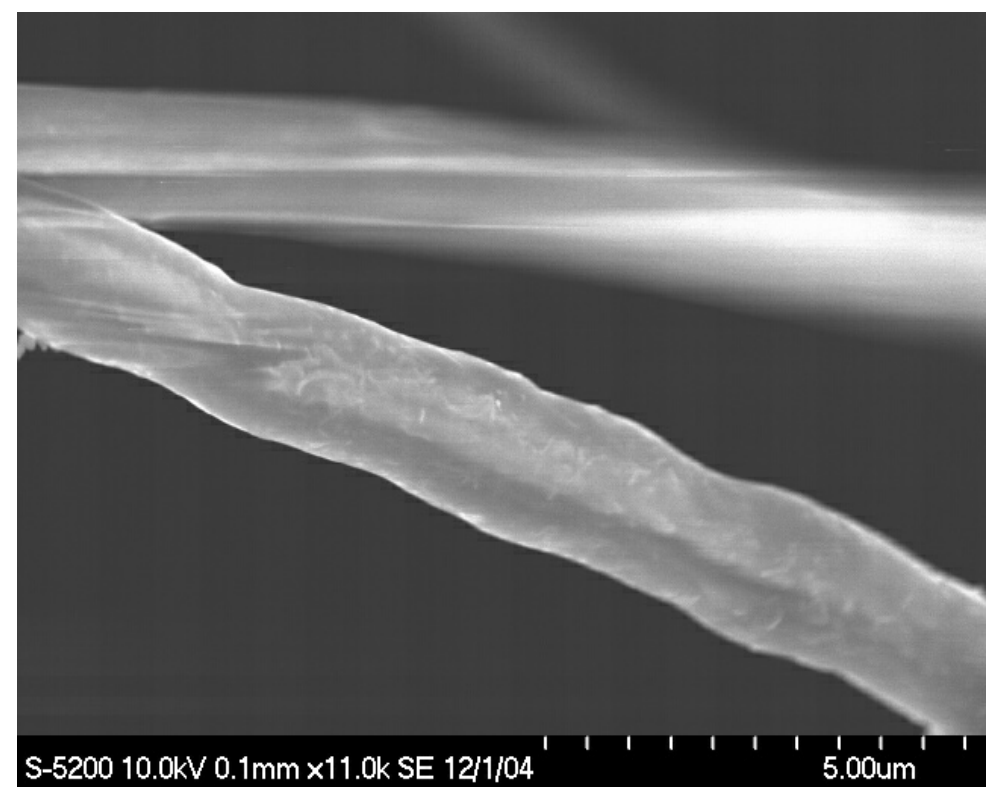

Figure 10. HRSEM image of electrospun fiber

Fibers were cut with a razor blade prior to imaging by HRSEM and at the fractured end, SWNTs can be seen protruding and appear to be oriented parallel to the fiber axis (Figure 11).

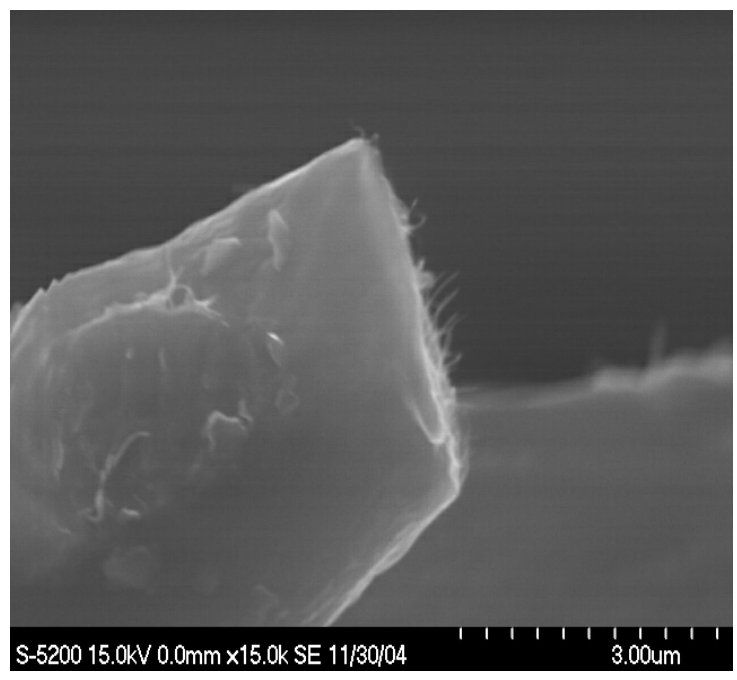

Figure 11. HRSEM showing fractured end 


\section{Summary}

Polyimides prepared with AFDA and various aromatic dianhydrides were tested for their effectiveness at dispersing SWNTs. Three polyimides were successful at dispersing the SWNTs in DMAc. P1 was insoluble and required a reduction in molecular weight before films and fibers could be prepared. However, P3 was soluble at high molecular weight. Films prepared from both polyimides showed random dispersion of SWNTs by HRSEM. Incomplete dispersion of SWNT bundles were seen in the 0.5 and the $1 \mathrm{wt} \% \mathrm{P} 3$ films and the $1 \mathrm{wt} \%$ EP3 film. Increased electrical conductivity was seen in the nanocomposite films, however electrical percolation occurred at higher loadings than are typically expected for polyimide/SWNT nanocomposites. Modulus of the films increased slightly with higher SWNT loading, though the strength of the films did not change as a function of SWNT loading. Elongation of the P3 films diminished as a result of SWNT loading. Electrospun fibers were prepared from the same polyimide/SWNT suspensions used to prepare the films. HRSEM showed that the SWNTs were captured in the interior of the fiber and may have some directionality parallel with the fiber axis.

\section{References}

1) Watson KA, Ghose S, Delozier, DM, Smith Jr. JG, and Connell JW. Polymer, 46, 2076 (2005).

2) Watson KA, Smith Jr. JG, and Connell JW. Society for the Advancement of Materials and Process Engineering Technical Conference Series 2001;33:1551.

3) Smith Jr. JG, Watson KA, Thompson CM, Connell JW. Society for the Advancement of Materials and Process Engineering Technical Conference Series 2002;34:365.

4) Smith Jr. JG, Connell JW, Lillehei P, Watson KA, and Thompson CM. Materials Research SocietySpring 2002 Session T, On-line Proceedings, 2002;733E:T3.5. www.mrs.org/publications/epubs/proceedings/spring2002/t/.

5) Park C, Ounaies Z, Watson KA, Crooks RE, Smith Jr. JG, Lowther SE, Connell JW, Siochi EJ, Harrison JS and St. Clair TL. Chem Phys Lett 2002;364:303. 
6) Smith, J.G. Jr., Delozier, D.M., Connell, J.W., and Watson, K.A.; "Carbon NanotubeConductive Additive-Space Durable Polymer Nanocomposite Films for Electrostatic Charge Dissipation", Polymer, 45 (18), 6133 (2004).

7) Delozier DM, Watson KA, Smith Jr. JG, and Connell JW. Composite Science and Technology 2005;65:749.

8) Park C, Ounaies Z, Watson KA, Crooks RE, Smith Jr. JG, Lowther SE, Connell JW, Siochi EJ, Harrison JS and St. Clair TL. Chem Phys Lett 2002;364:303.

9) Lin T, Bajpai V, Ji T, and Dai L. Aust. J. Chem. 2003;56:635.

10) Mukhopadhyay K, Dwivedi CD, Mathur GN. Carbon 2002;40:1373-76.

11) Chen J, Hamon MA, Hu H, Chen Y, Rao AM, Eklund PC and Haddon RC. Science 1998;282:95.

12) Niyogi S, Hamon MA, Hu H, Zhao B, Bhowmik P, Sen R, Itkis ME and Haddon

RC. Acc. Chem. Res. 2002;35:1105.

13) Sun Y-P, Fu K, Lin Y and Huang W. Acc Chem Res 2002;35:1096.

14) Hill DE, Lin Y, Rao AM, Allard LF and Sun Y-P. Macromolecules 2002;35:9466.

15) Aizawa M and Shaffer MSP. Chem. Phys. Lett. 2003;368:121.

16) Banerjee S and Wong SS. JACS 2002;124:8940.

17) Bahr JL and Tour JM. Chem Mater. 2001;13:3823.

18) Dyke CA and Tour JM. JACS 2003;125:1156.

19) Holzinger M, Abraham J, Whelan P, Graupner R, Ley L, Henrich F, Kappes M and Hirsch A. JACS 2003;125:8566.

20) Smith Jr. JG, Connell JW, Delozier DM, Lillehei PT, Watson KA, Lin Y, Zhou B, and Sun YP. Polymer 2004;45:825.

21) Islam MF, Rojas E, Bergey DM, Johnson AT and Yodh AG. Nano Lett 2002;3:269.

22) Star A, Liu Y, Gant K, Ridvan L, Stoddart JF, Steuerman DW, Diehl MR, Boukai A, and Heath JR. Macromolecules 2003;36:553.

23) Chen RJ, Zhang Y, Wang D, Dai H. JACS 2001;123: 3838.

24) Star A, Steuerman DW, Heath JR and Stoddart JF. Agnew. Chem. Int. Ed. 2002;41: 2508.

25) Hirsch A. Angew. Chem. Int. Ed. 2002;41:1853.

26) Ago H, Shaffer MSP, Ginger DS, Windle AH, Friend RH. Phys. Rev. B: Conden. Mat. Mater. Phys 2000;61:2286.

27) O'Connell MJ, Boul P, Ericson LM, Huffman C, Wang Y, Haroz E, Kuper C, Tour J, Ausman KD, Smalley RE. Chem Phys Lett 2001;342:265.

28) Curran S, Ajayan PM, Blau WJ, Carroll DL, Coleman JN, Dalton AB, Davey AP, Drury A, McCarthy B, Maier S, Stevens A. Adv Mater 1998;10:1091.

29) Coleman JN, Dalton AB, Curran S, Rubio A, Davey AP, Drury A, McCarthy B, Lahr B, Ajayan PM, Roth S, Barklie RC, Blau WJ. Adv Mater 2000;12:213.

30) Curran S, Davey AP, Coleman JN, Dalton AB, McCarthy B, Maier S, Drury A, Gray D, Brennan M, Ryder K, La Chapelle ML, Journet C, Bernier P, Bryne HJ, Carroll D, Ajayan PM, Lefrant S, Blau W. Synth Met 1999;103:2559.

31) McCarthy B, Coleman JN, Czerw R, Dalton AB, Carroll DL, Blau WJ. Synth Met 2001;121:1225.

32) Dalton AB, Stephan C, Coleman JN, McCarthy B, Ajayan PM, Lefrant S, Bernier P, Blau WJ, Bryne HJ. J Phys Chem B 2000;104:10012. 
33) Steuerman DW, Star A, Narizzano R, Choi H, Ries RS, Nicolini C, Stoddart JF, Heath JR. J Phys Chem B 2002;106:3124.

34) Wise KE, Park C, Siochi EJ, Harrison JS. Chem Phys Lett 2004;391:207.

35) Star A, Stoddart JF, Steuerman DW, Diehl M, Boukai A, Wong EW, Yang X, Chung SW, Choi H, Heath JR. Agnew Chem Int Ed 2001;40:1721.

36) Xu H, Tang BZ. Polym Mater Sci Eng 1999;80:408.

37) Wang J, Musameh M, Lin Y. JACS 2003;125:2408.

38) Landi BJ, Raffaelle RP, Heben MJ, Alleman JL, VanDerveer W, Gennett T. Nano Lett 2002;2:1329.

39) Fukushima T, Kosaka A, Ishimura $Y$, Yamamoto T, Takigawa T, Ishii N, Aida T. Science 2003;300:2072.

40) Delozier, DM, Tigelaar, DM, Watson, KA Smith, JG, Jr., Lillehei PT, and Connell, JW. Polymer 2005;46:2506.

41) Zhou H, Chen C, Kanbara R, Sasaki T, Yokota R. High Perform Poly 2005; 17:213.

42) Siochi EJ, Working DC, Park C, Lillehei PT, Rouse JH, Topping CC, Bhattacharyya

AR, Kumar S. Composites: Part B 2004;35:439.

43) Shaefer DW, Zhao J, Brown JM, Anderson DP, Tomlin DW. Chem Phys Lett 2003;375:369. 